\section{Beitrag zur Casuistik der Impftuberculose beim Menschen.}

\section{Von Dr. Paul Gerber in Königsberg i. Pr.}

Mittheilungen über Fälle von Impftuberculose finden sich in der Litteratur zuerst im Jahre 1883, wenn auch viele der mitgetheilten Beobachtungen in eine viel frühere Zeit zurückreichen. ${ }^{1}$ ) Doch ist unter den mitgetheilten Fällen eine ganze Reihe solcher, die nicht eindeutig und einwurfsfrei sind, und von denen man nicht die Ueberzengung gewinnt, dass es sich bei ihnen wirklich um eine lediglich von aussen her, durch Einimpfung acquirirte Tuberculose handelt. Denn hereditäre Belastung und oft schon anderweitig im Organismus zum Ausdruck gelangte Tuberculose spielen vielfach hinein, $\left.{ }^{2}\right)$ sodass man sich angesichts solcher Fälle fragen muss, ob es sich hier nicht vielmehr um eine früher latent gewesene 'Tuberculose handelt, die durch irgend eine Gelegenheitsursache zur Erscheinung gekommen ist, wie wir das so oft bei der sogenannten "chirurgischen Tuberculose" beobachten können. ${ }^{3}$ ) Die reinsten Fälle von Impftuberculose werden naturgemäss die sein, bei denen hereditäre Belastung sowie jede frühere tuberculöse Erkrankung ausgeschlossen, und eine infection beim Ungehen mit irgend welchem tuberculösen Material nachgewiesen werden kann. Doch genügen diesen drei Anforderungen zugleich nur sehr wenige Fälle.

Von grösstem theoretischen wie praktischen Interesse sind jene Fälle, in welchen die Impftuberculose zur Erkrankung entfernterer Theile, wie $z$. B. der Lymphdrïsen führte. Ich will daher in Folgendem zunächst in aller Kürze diejenigen Fälle zusammenstellen, in denen es zu einer wirklichen Drïsentuberculose gekommen ist, und in denen man mit mehr oder minder grosser Wahrscheinlichkeit eine direkte Inoculation mit tuberculösem Virus von aussen annehmen kann. Im Anschluss daran werde ich mir dann eslauben, einen neuen Fall mitzutheilen, für den ich um so mehr einstehen kann, als er an mir selbst zur Beobachtung kam.

An Klarheit obenan steht der Fall vou Tscherning. ${ }^{4}$ ) Er betrifft ein junges Mädchen, das weder hereditär belastet noch selbst jemals scrophulös gewesen ist. Dasselbe schnitt sich mit dem Scberben eines Spuckgefässes, das phthisisches, sehr bacillenreiches Sputum enthielt, an der Volarseite der ersten Phalanx des Mittelfingers ein, worauf sich im Verlauf mebrerer Monate an dem verletzten Finger eine tuberculöse 'Tendovaginitis und im Anschluss daran eine Tuberculose der Cubital- utd Axillardrüsen derselben Seite entwickelte. Die erkrankten Theile wurden entfernt und in ihnen Riesenzelltuberkel und Bacillen nachgewiesen. Zwei Monate nach der Operation war Patientin vollkommen gesund, und es entstand weder in der Narbe ein Recidiv noch anderweitige Drïsenanschwellung; auch waren von Seiten der inneren Organe keine Erscheinungen hinzugekommen.

Karg ${ }^{5}$ ) theilt die Krankengeschichte eines Mannes mit, der, hereditär nicht belastet, verheirathet und Vater von zwei gesunden Kindern, - vorübergehend als Leichendiener angestellt war und dabei einen sogenannten. Leichentuberkel acquirirte. Trotz der verschiedensten Mittel konnte er nicht zur Heilung gebracht werden, ja er schwoll sogar nach einigen Jahren wieder stärker an, und zugleich traten im Verlauf der abführenden Lymphgefässe mehrere suppurirende Knoten auf. - In den operativ entfernten Theilen konnten typische Riesenzelltuberkel und vereinzelte Bacillen nachgewiesen werden. - Die Wunden heilten gut, und es zeigten sich keine Symptome anderweitiger Tuberculose.

Von den zwei von Leser.6) mitgetheilten Fällen repräsentirt nur der eine eine reine Impftuberculose, wenn auch seine Aetiologie völlig unsicher ist.

1) Die bis zu 1887 publicirten Fälle finden sich zusammengestellt im Jahresbericht über d. Fortschritt i. d. Thehre von den pathogenen Mikroorganismen von Baumgarten. Bd. I, 1885 u. Bd. IT, 1886.

2) So in den Fällen von Kraske, Hanot, Wahl und einem Fill ron Leser.

3) Vgl. Baumgarten's Jahresbericht.

4) E. A. Tscherning, Inoculationstuberculose beirn Mensehen. Fortschritte d. Med. 1885 , No. 3, p. 65.

5) Karg, Tuberkelbacillen in einem sogenannten Leichentuberkel. Centralbl. f. Chirurgie 1885, No. 32, p. 565.

6) Leser, Klinischer Beitrag zur Lehre von der tuberculösen Infection. Fortschr. d. Yed. 1887, No. 16.
Eine 54jährige, hereditär nicht belastete Frau zieht sich einte kleine Schnittwunde an der Nagelphalanx des rechten Daumens zu, die zu einer fungösen Tuberculose der Haut und des Unterhantzellgewebes der betreffenden Phalanx und im weiteren Verlauf zu denselben Erscheinungen an der Nagelphalanx des rechten Zeigefingers und schliesslich zur 'Tuberculose der Oberarm- und Axillarlymphdrüsen und einer tuberculösen Erkrankung des retromammalen Zellgewebes der betreffenden. Seite führell. - In den entfernten fungösen Massen der Finger, der Lymphdrüsen und in dem retromammalen Abscesse liessen sich typische Tuberkelknoten und ziemlich reichliche Tuberkelbacillen nachweisen.

Eine ganze Reihe von Beobachtungen liegt vor über Fälle von Impftuberculose, die durch das in niedrigen jüdischen Volksclassen noch vielfach ïbliche Aussaugen der rituellen Circumcisionswunden durch phthisische Beschneider entstanden sein soll. Obgleich nun in vielen Fällen wohl die Heredität eine Rolle spielen mag, in manchen - die Beobachtungen reichen bis in's Jahr 1873 zurïck weder die histologische noch bacterioskopische Untersuchung vorgenommen wurde, - so kann man sich doch bei dem meist typischen Verlanf dieser Fälle kaum der Ansicht verschliessen, dass es sich hier meist um eine wirkliche Impituberculose handelt, die nur vielleicht in ihrem verschiedenen Verlauf durch die verschiedene ererbte Disposition der Kinder beeinflusst wird.

Hierzu gehören die Fälle von Lindmann, 1) Lehmann, ?) Hofmokl, 3) Elsenber.g ${ }^{4}$ ) und W. Meyer. ${ }^{5}$ - Der Sach verhalt ist meist folgender: Mehrere Kinder werden ron einem mit notorischer Lungentuberculose behafteten Beschneider circumcidirt und die Circumcisionswunden ausgesogen. Es entwickeln sich an diesen Wunden geschwürige Affectionen, die zur Intumescenz der Leistendrïsen und weiterhin entweder zu acuter Tuberculose, an der die Kinder zu Grunde gehen, oder zu schweren scrophuloseartigen Krankheiten führen. - In der Mittheilung von Lindmann stirbt das hereditär belastete Kind, das nicht belastete überwindet die Infection. Bei Lindmann sowohl wie bei Lehmann stirbt der Beschneider bald nach den betreffenden Beschneidungen an seiner Tuberculose. Bei Elsenberg werden die Bacillen im Sputum des Beschneiders, bei ihm wie bei Hof exstirpirten Theilen der Kinder nachgewiesen.

In einer anderen Reihe ron Fällen ist eine äussere Verletzung, die die Eingangspforte für das tuberculöse Virus gebildet hätte, nicht nachzuweisen. In allen diesen Fällen handelt es sich un früher gesunde, hereditär nicht belastete Franen, die mit der Pflege, resp. der Wäsche phthisischer Personen zu thun hatten, und bei denen es dann bald zu atonischen Ulcerationen, bald zu tuberkelartigen Knoten auf dem Handrücken oder dem unteren Theile des Vorderarmes kommt, oder zuerst zu einem Panaritium, das zu einem chronischen Geschwür wird, wobei dann in den entfernten Massen meist Riesenzelltuberkel und Bacillen nachgewiesen werden.

$\mathrm{Zu}$ dieser Gruppe gebören die Fälle von Merklèn, 6) Holst, 7) Steinthal,$^{8}$ ) v. $\operatorname{Lesser}^{9}$ ) und H. B. Schmidt. ${ }^{10}$ ) - v. Lesser nun stellt im Anschluss an seinen Fall die Vermuthung auf, dass die Schweissdrüssen die Eingangspforte für das tuberculöse Gift bilden kőnnten, - - uns aber scheint die Moglichkeit doch viel näher zı liegen, dass in diesen Fällen kleine unbeachtete Läsionen der Finger und der Hand, wie wir sie uns ja tausendfach zuziehen, und wie sie an den Händen der arbeitenden Bevölkerung selten zu vermissen sind, die Eingangspforte bildeten.

Za einer nachweislich tuberculösen Lymphadenitis kam es nur in dem Falle von. Holst. Dieser betrifft eine Krankenwärterin, die phthisische Patienten pflegte, nnd bei der sich atonische Ulcerationen der Finger bildeten, die sehr lange Zeit bestanden und trotz der verschiedensten Mittel nicht zur Heilung kamen! Vielmehr entwickelte sich eine Anschwellung der Axillardrüsen derselben Seite. In den Ulcerationen der Finger gelang es nicht sicher, wohl aber in den Drïsen, Tuberkelbacillen nachzuweisen.

1) Lindnaun, Ein Beitrag zur Contagiosität der' '́nberculose. Dentsche med. Wochenschr. 1883 , No. 30 .

2) E. Lehmann, Ueber einen Modus von Imptuberculose beim Menschen, die Aetiologie der Tuberculose und ihr Verhãltniss zur Scrophulose. Deutsche med. Wochensehr. 1886, No. 9-13.

3) 11 o fmokl. Wiener med. Presse 1886, No. 22 u. 23, p. 749.

4) A. Elsenberg, Inoculation der Tuberculose bei einem Kinde. Berliner klin. Wochenschr. 1886 , No. 35 , p. 581 .

5) W. Heyer, Ein Fall von Impftuberculose in Folge ritueller (iicumcision. New-Yorker med. Presse. Juni 1887.

6) Soc. méd. d. hôp. 1885.

7 Axel Holst, Tubercular inoculation in a man. The Lancet, vol If No. $9,1886,16$ Oet.

$\left.{ }^{8}\right)$ C. F. Steinthal, Ueber Hauttuberculose durch Inoculation und Autoinfection. Deutsche med. Wochenschr. 1888, No. 10, p. 184.

$\left.{ }^{9}\right)$ v. Lesser, Zur Impttuberculose von der Haut aus. Deutsche med. Wochenschr. 1888, No. 29, p. 592.

$\left.{ }^{10}\right)$ II. B. Sclimidt, Arbeitell aus der chirurg. Poliklinik. Leipzig 1888. 
Mein Fall ist folgender:

Bei einer im'November vorigen Jahres (1887) ausgeführten Section zog ich mir beim Schnitt durch die, mit älteren und neueren tuberculösen Herden reichlich durchsetzte Lunge einer alten, an Phthisis pulmonum gestorbenen Frau eine kleine Wunde in der Gegend des ersten Interphalangealgelenkes des kleinen Fingers der linken Hand zu, die ich nach bald darauf beendeter Section mit $5 \%$ Carbolwasser ausspülte. In der darauf folgenden Nacht fühlte ich Schmerzen im Finger und an der Hand und fand am mächsten Morgen den Finger etwas geschwollen und geröthet, und zog sich die Röthung an der Ulnarseite der Hand bis über das Handgelenk hinauf die kleine Wunde selbst war geschlossen. Es wurde nun die Wunde wieder geöffnet und dilatirt und feuchtwarme Umschlăge mit essigsaurer 'Thonerde applicirt. 'Temperatur über $38^{\circ}$. Appetitlosigkeit. Am nächsten Tage war Schwellung und Röthung zurückgegangen und das Allgemeinbefinden ein ganz normales. Die Wunde aber heilte nicht zu, sondern es bildete sich im Laufe der nächsten Tage an ihrer Stelle ein etwa kirschkerngrosses Knötchen, das von sehr dünner graublauer Haut bedeckt und an einigen Punkten sehr schmerzhaft war, und aus dem sich dann und wann ein wenig dünner grauer Eiter ausdrücken liess. Da ich nun damals sehr in Anspruch genommen war, verschob ich, in der Hoffnung, dass vielleicht doch Spontanheilung eintreten würde, eine radikalere Behandlung des Fingers auf eine gelegenere Zeit Da mun auch im März dieses Jahres (1888) sich nichts daran geändert hatte, so wurde von Herrn Dr. Will die Anschwellung incidirt, das schwamnige Gewebe mit der Scheere abgetragen und ein Jodoformverband angelegt. Gerade all dieser Zeit aber stellten sich leichte Schmerzen in der linken Achselhöhle ein, die an der Innenseite des Oberarmes nach dem Ellenbogen zu ausstrahlten; es zeigte sich auch bald in der Achselhöbì ein Paquet von 5 bis 6 intumescirten Drüsen; auch waren die linken Infraclaviculard rüsen, weln auch in geringerem Grade, angeschwollen. Nach einigen Tagen, il denen die Drüsen trotz angewandter Eisumschläge unverändert blieben, stellte sich hohes Fieber ein. Ich verfiel in einen etwa sieben Wochen dauernden typhusälınlichen Zustand, der einen remittirenden Fiebertypus und eille auffällige Depression des Nervensystems \%eigte, so dass mein Zustand vou meinem Collegen auch als eine typhoide Erkiankung aufgefasst wurde.

Die Wunde am Finger war einstweilen verheilt, und während dieser gaulen Zeit hatten die Drüsen keinerlei schmerhafte Erscheinungen gemacht; auch hatte die Schwellung weder $\%$ - noch abgenommen. Bald nachdem das Fieber aber geschwunden war und mein Gesammtbefinden sich erheblich gebessert hatte, begannen die Schmerzen in den Axillardrüsen auf's neue und waren nur durch immerwährende Application des Eisbeutels zu besänftigen. Dabei blieben die Drüsen anscheinend unverändert, wenigstens zeigten sie keine Neigung, weder zu einer regressiven, noclı progressiven Veränderung. Im Mai stellte ich mich nun Herrn Prof. Mikulicz vor, der etwa folgenden Status bei mir constatirte: In der linken Achselhöhle fühlt man einen über gänseeigrossen 'Tumor, der gegen den Pectoralis verschieblich ist, ebenso regen die Haut, welche selbst gänylich unverändert ist. Auf I)ruck verursacht der Tunnor lebhaften Schmerz. Ferner fühlt man unterlalb der Glavicula drei erbsengrosse, harte, bewegliche Knötchen. Herr Prof. Mik ulicz zweifelte nicht, dass es sich um 'Tuberculose der Lymphdrüsen handle, und schlıg mir die Exstirpation derselben vor.

Am 5. Juni wurden die Tumoren von der Achselhöhle aus exstirpirt. Sie stellen sich als erbsen- bis überwallnussgrosse Drüsen dar; alle grösseren sind verkäst. Auf dem Durchschnitt erscheint der Rand grau-opak, die Nitte gelb. In der Uebergangszone zwischen dem normalen Rande und dem verkästen Centrum deutliche Riesenzelltuberkel. Die bacterioskopische Untersuchung ergiebt zwar nicht zablreiche aber cleutliche T'uberkelbacillen.

Da während der Operation wiederholt etwas von dem verkästen Drüseniuhalt auf die Wundfläehe gekommen war, verzichtete Herr Prof. Mikulicz absichtlich auf eine primäre Vereinigung del Wunde; dieselbe wird vollständig mit Jodoformgazestreifen tamponirt.

l)ie Heilung erfolgte ohne nennenswerthe Zwischenfälle, und konnte ich aın 5. Juli mit völlig vernarbter Wunde eine Badereise antreten.

Die Narbe ist bis jetzt (Mitte Deceinber) voll eimen Recidiv freigeblieben, ebensowenig sind anderweitig Drüsenerkiankungen oder Symptome einer Erkrankung innerer Organe eingetreteu. Ich war durch die ganze Krankheit in meiner Ernährung sehr beruntergekommen und latte vor der Operation ein auffallend anämisches Aussehen. Nach derselben aber erholte ich mich sehr rasch und erfreue mich seit dieser Zeit wieder meines alten Wohlbefindens.

Ich füge hin\%u, dass ich aus durchaus gesunder Familie stanme, in der insbesondere Brustkrankheiten nicht beobachtet sind. Ich selbst habe nie Zeichen irgend einer tuberculösen krkrankung dargeboten, wie denn auch meine inneren Organe als vollkommen normal befunden wurden.

Mein Fall erfüllt, wie ich glaube, alle die Forderungen, die man an einen reinen Fall von Impftuberculose stellen muss, und deshalb glaube ich mich einer Epikrise ganz enthalten zu können.

Diese Mittheilungen waren schon beendet, als ich noch auf einen neuerdings veröffentlichten Fall von Impftuberculose aufmerksam gemacht wurde. ${ }^{1}$ )

Derselbe betrifft ein 14 jăhriges Mädchen, das von luetischen Eltern, aber aus tuberculös nicht belasteter Familie stammt. Dieselbe entnahm einer vor $1 \frac{1}{2}$ Jahren an Phthisis gestorbenen Freundin bald nach ihrem Tode die Ohrringe und befestigte sie in ihren eigenen Obren. Bald darauf wurden diese wund, und aus den Ohrringöffnungen entleerte sich Secret. 1)a das Geschwür nicht heilen wollte, vielmehr am Halse ein anderes auftrat, das Mädchen elend wurde und hustete, wurde sie dem Verf. zugeführt, der an linken Ohrläppchen, von der Durchbohrungsstelle ausgehend, ein schlecht aus-

1) Casuistische Mittheilungen aus Dr. Unna's Poliklinik f. Jlautkrankheiten, von Dr. E. v. Düring. Monatsh. f. prakt. Dermatologie 1888, No. 22. p. 1128 . sehendes Geschwür mit unterminirten Rändern fand. An der linken Halsseite eine grosse derbe Drüse, mit der Haut verwachsen, diese ulcerirt und mit missfarbenem Schorf bedeckt. - In der linken Lungenspitze Dämpfung, vorn bis unterhalb der Clavicula reichend; spärliche Rasselgeräusche.

In den mit dem scharfen Löffel entfernten Granulationsmassen werden - ebenso wie im Sputum - Tuberkelbacillen nachgewiesell. Während die localen Processe sich bessern, sind schon im Juni beide Spitzen und die linke Lunge ganz infiltrirt. Jetzt befindet Patientin sich im letzten Stadium der Phthise.

Auch in diesem Falle glaubt der Verf. alle an einell reinen Fall von Impftuberculose zu stellenden Forderungen erfïllt zu sehen. Trotzdem gewinnt man aus der Mittheilung nicht die Ueberzengung, dass Patientin früher durchaus gesund gewesell ist, speciell dass die Affection der linken Lungenspitze nicht schon vor der localen Infection bestanden hat. Es wäre dies - ausser dem Fall vou Pfeiffe ${ }^{1}$ ) - der einzige, bei dem es bei einem erwachsenen, bis dahin gesunden Menschen nach einer Impftuberculose $\%$ einer tuberculösen Allgemeinerkrankung, und zumal so rapide, gekommen ist; es liegt hier wohl ungleich näher, anzunehmen, dass die locale Infection einen bis dahin im Organismus nur schlummernden Process geweckt hat, und dass beide zusammen dann die so rapide Entwickelung der Allgemeinerkrankung herbeigeführt haben, wenn wir überhaupt einen causalen Zusammenhang zwischen dem Geschwür am Ohrläppchen und der Erkrankung der Lungen zugeben sollen.
1) L. Pfeitifer, Ein neuer Fall von Uebertragung der 'Tuberculose des Rindes auf d. Menschell. Zeitschr. f. Hygiene Bd. III, 1887, p. 189 